\title{
Hysterectomy: A leading cause of iatrogenic ureteric injuries in obstetric and gynaecologic surgeries
}

\author{
R Dushyant ${ }^{1}$, JainS ${ }^{2}$ \\ ${ }^{1}$ Dr Dushyant Rohit, Assistant Professor, Department of Surgery, Bundelkhand Medical college, Sagar, MP, India \\ ${ }^{2}$ Dr Sheela Jain, Assistant Professor, Obstetrics and gynaecology, Bundelkhand Medical college, Sagar, MP, India
}

Address for correspondence: Dr Dushyant Rohit, Email- dushyant039@gmail.com

\begin{abstract}
Background: This study was done to share our surgical experience of iatrogenic ureteric injuries from obstetric and gynecological surgeries treated in the department of surgery Bundelkhand Medical College Sagar, MP, India. Material and Method: A prospective study of 18 women who were treated for iatrogenic ureteric and bladder injuries secondary to obstetric and gynecological procedures in the department of surgery Bundelkhand Medical College, Sagar between 2010 \& 2012. Results: In our study 18 cases were managed. 3 cases were treated for intra-operative injury by primary repair. Patients who ware diagnose later in course of disease were undergone Psoas hitch repair, had prolonged hospitalization with extra cost of treatment .Conclusion: Alhough ureteric injury is quite rare in obstetric \& gynecological surgery but it is still a reality, to avoid it high degree of suspicion and careful tissue dissection is required. Intra-operative diagnosis had an excellent result but late diagnosis was associated with high morbidity.
\end{abstract}

Keyword: Ureteric injuries, Hysterectomy, Carcinoma cervix

\section{Introduction}

Iatrogenic ureteric injuries are rare serious complications of obstetric and gynaecologic surgeries but associated with high morbidity due to the risk of infection, urine leak and possible loss of renal function. The estimated incidence of ureteral injury during major gynecologic surgery is $0.5 \%$ to $2.5 \%$, and abdominal hysterectomy accounts for over half of the total [1,2] and among the obstetric procedures, cesarean section is clearly the most common reason [3].

Most of these injuries occur at the time of haemostatic suturing, when sutures are placed at the side of the uterus during hysterectomy especially when bleeding is excessive and blind clamps are applied to stop the bleeding [4]

Despite the close anatomical association between the female reproductive organs and the ureter, injury to the ureter is relatively uncommon. But still these injuries occur as the ureters run close to the field of dissection [5- 7] and availability of limited surgical space. Numerous consequences may occur after ureteric injury, including spontaneous resolution and healing of the injured ureter, hydronephrosis, ureteral necrosis with urinary

Manuscript received: $09^{\text {th }}$ Feb 2014

Reviewed: $15^{\text {th }}$ Mar 2014

Author Corrected: $23^{\text {rd }}$ Mar 2014

Accepted for Publication: 30 ${ }^{\text {th }}$ April 2014 extravasations, ureteral stricture formation and uremia. Surgical procedures responsible for ureteric injuries are total abdominal hysterectomy, Radical Hysterectomy, emergency Hysterectomy. Other rare causes are secondary to cervicocystopexies both pubic or vaginal, ovarian surgeries and uterine aspiration. The most reliable methods to avoid iatrogenic ureteric injury are generous surgical exposure, meticulous surgical technique, and to clearly identify the ureter throughout the operative field. Though the best way to avoid these injuries is preoperative ureteric catheterization but this facility is not available in rural hospital. Studies suggest prognosis is better when injury is detected intraoperatively and primary repair is performed. But the preoperative detection rate is very less.

\section{Material and Method}

This study was done in the department of surgery, Bundelkhand Medical College Hospital, Sagar (MP) in prospective method. Study was permitted by Institutional Ethical Committee. This study was done from August 2010 to December 2012. All Eighteen patients case notes were retrieved from the medical records and analysed in detail the patients name, age and name of the referring hospital. A detailed history with 
particular reference to surgical procedures was noted. In every patient history, physical examination was carried out. Base line laboratory investigations including blood, urine, urine culture and sensivity and Renal Function tests (Blood urea, Serium creatinine, and Electrolytes) were done. Radiological evaluation by ultrasound KUB, IVP, retrograde or ante grade pyelogram was performed in all cases to define the level and extent of ureteral injury.

Eighteen patients were included in this study, all develop this injury after Hysterectomy in District Hospital. Out of these Eighteen patients, Six patients develop ureteric injury after hysterectomy for Carcinoma Cervix, four Patients after low anterior cervical fibroid and eight patients develop it after emergency Hysterectomy for uncontrolled PPH.

All patients were treated with surgical exploration through a little lateral extension of existing Pfannstiel incision which was given during previous procedure. The approach was completely retroperitoneal, after identifying the ureter it was dissected above and below the fibrosis and Psoas Hitch repair was done over D-J stent with layered closure of abdomen. Three (3) cases was diagnosed intra-operatively, in these cases loss of ureter length is minimal so primary repair was done after mobilization. The length of hospital stay of patient whose injury was diagnose intra-operatively was not different from other Hysterectomy patient (8 days) but in patient whose injury was diagnose postoperatively, hospital stay was 19.6 days.

\section{Result}

In our study, we retrospectively examined the Eighteen cases of ureteric injury after hysterectomy, in which six patients underwent Hysterectomy for $\mathrm{Ca} \mathrm{CX}$, four patients for low anterior cervical fibroid uterus and eight cases for emergency Hysterectomy due to uncontrolled PPH. Median time since the time of injury and presentation was about 2 weeks.

All patients main complaint was continuous urinary incontinence within 2 weeks of surgery. All the patients were aseptic on presentation and renal function tests were normal. Initial radiological investigation was ultrasound (done prior to referral), which showed unilateral hydronephrosis in all cases, and one of the case showed small pelvic collection.

In all cases we found lower ureteric injury. Three cases of ureteric injury was diagnosed intra-operative for which primary repair with D-J stent was done with excellent post operative result, But in fifteen patients were diagnosed post-operatively as a urinary fistula with added morbidity. In all these cases Psoas hitch repair was done with D-J stent with excellent outcome but with prolonged hospitalization. Double J sent was removed after 4 weeks. Patients were followed up to 3 months. Upon the follow up, Intravenous Urogram was done which showed normal study in all cases, no residual hydronephrosis and no reflux.

Table 1: Indication for hysterectomy, site of ureteric injury and time of diagnosis

\begin{tabular}{|c|c|c|c|c|c|}
\hline S.N. & \multirow{2}{*}{$\begin{array}{c}\text { Indication for } \\
\text { hysterectomy }\end{array}$} & \multirow{2}{*}{$\begin{array}{c}\text { N- of } \\
\text { cases }\end{array}$} & \multirow{2}{*}{$\begin{array}{c}\text { Site of } \\
\text { injuries }\end{array}$} & \multicolumn{2}{|c|}{ Time of diagnosis } \\
\cline { 4 - 6 } & Carcinoma cervix & 6 & lower & Intraoperative & Postoperative \\
\hline 1 & $\begin{array}{c}\text { Low anterior uterine } \\
\text { fibroid }\end{array}$ & 4 & lower & 1 & 3 \\
\hline 3 & $\begin{array}{c}\text { Emergency } \\
\text { hysterectomy for } \\
\text { uncontrolled PPH }\end{array}$ & 8 & lower & nil & 8 \\
\hline
\end{tabular}

\section{Discussion}

Normal length of ureter is $25-30 \mathrm{~cm}$ and a diameter of 3 $\mathrm{mm}$ in adult. The abdominal part lies anteriorly on the psoas muscle and at the level where the common iliac artery bifurcates into the internal and external iliac arteries, it crosses the internal iliac vessels to enter the pelvis. The ovarian vessels travel in the infundibulopelvic ligament of the ovary and cross the ureter anteriorly and laterally to the iliac vessels. The anteromedial surface of the ureter is covered by peritoneum, and it runs posterior to the ovary and then deep into the broad ligament and through the cardinal ligament. The uterine artery accompanies the ureter as it passes on the lateral lower aspect of the uterus and superior portion of the vagina. At the base of the cardinal ligament, the ureter passes over the uterine artery. At this zone it is often called "genou de l'uretere" because it changes its direction. At this point the ureter is about $12 \mathrm{~mm}$ from the wall of the vagina. As it passes to enter 
the base of the bladder it becomes even more close to the anterior wall of the vagina $[8,9]$. The blood supply to the upper third of the ureters comes from the renal and ovarian arteries, the middle third is supplied by the aortic branches and the common iliac arteries, and the lower third, by the uterine, vaginal, middle haemorrhoidal, vesical and hypogastric vessels. There are four critical points of potential ureteral injury during a hysterectomy. The first critical point is situated at the entrance of the ureter in the pelvic bone, when the ovarian vessels cross over it. The second critical point is identified next to the uterosacral ligament, where the ureter is situated lateral to this ligament. The third critical point is at the level of the uterine artery, where the ureter crosses below the uterine artery through the cardinal ligament at the level of the ischial spine. The fourth critical point occurs in the bladder, where the ureter turns medially, crossing the anterior portion of the vaginal dome and entering the bladder wall.

Iatrogenic ureteric injuries are frequently encountered during hysterectomies [10]. The Six most common mechanisms of operative ureteral injury are - Crushing from misapplication of a clamp, Ligation with a suture, Transsection (partial or complete), Angulation of the ureter with secondary obstruction, Ischemia from ureteral stripping or electrocoagulation, Resection of a segment of ureter. Any combination of these injuries may occur. The close proximityof the ureter to the uterus and cervix with limited exposure increase the chances of injury especially if the uterus is enlarged, the dissection is difficult due to malignancy and adhesions due to pelvic inflammatory disease radiation therapy, anatomical anomalies of the urinary tract also increases chances of injury $[11,12]$. Our series similarly demonstrated that abdominal hysterectomy was the most common cause for iatrogenic ureteric injuries.

The time at which ureteric injury is diagnosed determines the outcome for the patient. Intraoperative diagnosis allows for early repair of the ureteric injury which makes the repair easier compared to a delayed repair, and reduces morbidity and prolonged hospitalization. So Intraoprative detection of ureter injury is very important but unfortunately our study demonstrates that only $16.6 \%$ detected intra operatively. Intraoperative diagnosis is made when urinary leakage and extravasation is observed but this is not seen in many patients that have had major or vascular injuries [12]. Visual inspection may reveal ureteric wall discoloration and contusion, but it should be noted that ureteric vermiculation (visible spontaneous peristalsis to propel the urine through its lumen) does not exclude the possibility ureteric injury. When inspection is inconclusive, intraoperative recognition may be facilitated by intravenous injection of indigo carmine, which may

International Journal of Medical Research and Review confirm patency of the ureter by ejaculation of dye through the ureteric orifices and could be visualised at intraoperative cystoscopy. Intraoperative cystoscopy with dye and cystoscopic ureteral catheterisation both allow for early recognition of obstructive ureteral injuries, and so should be considered in complex surgical operations in gynaecology.

In general, preoperative detection of ureter injury was managed by primary repair but in case of late presentation due to fibrosis primary repair was not possible in such cases. Psoas hitch repair was performed with excellent result. Yousef S. Matani et al. found in their study that the time taken to detect the ureteric injury remains the most important morbidity-related factor [13]. JE Mensah, et al. found that Late recognition and referral of bilateral ureteric injury was associated with serious complications [14].

More than $70 \%$ of the time, unilateral ureteric injury is noticed postoperatively, when the patient may present with flank pain, prolonged ileus, fever, watery vaginal discharge, or elevated serum creatinine levels. In cases of bilateral ureteric injury, anuria is the first clinical sign. Investigations done included: ultrasound of the urinary tract, function test and intra-venous pyelogram. Cystoscopy and Veginoscopy as well as retrograde ureteric catheterization [15] and contrast studies were not done due to lack of facility. The aim of history taking, examination and investigations was to locate and delineate the injury so that surgical intervention can be planned. Definitive surgical interventions included, ureteric re-implantation [16].

Rafique $\mathrm{M}$ et al in their study found that Open surgical procedures for repair of iatrogenic ureteric injuries are a ssociated with good outcome[17].

\section{Conclusion}

Iatrogenic ureteric injuries from obstetric and gynaecologic surgeries are globally rare but are liable to occure due to the inherent anatomic and pathological factors in the pelvis. Intra-operative diagnosis of ureteric injuries is a rare feature and late diagnosis in the post operative period is more common. The awareness of the risk factors for genitourinary injury as well as the adoption of a few simple intraoperative (careful tissue dissection) precautions can aid in their prevention and eventual recognition at the time of surgery. Early recognition of these injuries and proper postoperative management serve to decrease patient morbidity. Late diagnosis of ureteric injuries was associated with high morbidity and psychological trauma to the patient and also cost effective.

Available online at: $\underline{\text { www.ijmrr.in }} 200$ | P a g e 
Funding: Nil

Conflict of interest: Nil

Permission from IRB: Yes

\section{References}

1. Symmonds RE. Ureteral injuries associated with gynecologic surgery: prevention and management. Clin Obstet Gynecol 1976 Sep; 19(3): 623-44.

2. Mattingly R E, Borkowf H I. Acute operative injury to the lower tract. Clin Obstet Gynecol 1978; 5:123-47.

3. Eisenhop S M, Richman R, Platt L D, Paul R H. Urinary tract injury during cesarean section. Obstet Gynecol 1982;60: 591-596.

4. Ustunsoz B, Ugurel S, Duru NK, Ozgok Y, Ustunsoz A. Percutaneous management of ureteral injuries that are diagnosed late after cesarean section. Korean J Radiol.2008 Aug;9(4):348-53.

5. Gilmour DT, Dwyer PL, Carey MP. Lower urinary tract injury during gynaecologic surgery and its detection by intra-operative cystoscopy. Obstet Gynecol. 1999 Nov; 94(5 Pt 2):883-9.

6. Mathevet P, Valencia P, Cousin C, Mellier G, Dargent D. Operative injuries during vaginal hysterectomy. Eur J Obstet Gynecol Reprod Biol. 2001 July;97(1):71-5.

7. Brubaker LT, Wilbanks GD. Urinary tract injuries in pelvic surgery. Surg Clin North Am. 1991 Oct;71(5): $963-$ 76.

8. Lei CC, Abdullah MM, Abdullah K. Iatrogenic Ureteric Injuries. Med J Malaysia. 1991 Jun;46 (2): 163 70 .
9. Polat O, Gul O, Aksoy Y, Uzbey I, Demirel A, Bayraktar Y. Iatrogenic Injuries to Ureter, Bladder and Urethra during Abdominal and Pelvic Operations. Int Urol Nephrol. 1997;29(1):13-8.

10. W. McDougal, Alan Wein, Louis Kavoussi, Andrew Novick, Alan Partin, Craig Peters, Parvati Ramchandani. Campbell-Walsh Urology ..campbell. $9^{\text {th }}$ ed.Philadelphia, Elsvier. Acute renal and ureteral trauma; p1283.

11. Gemer O, Simonovsky A, Huerta M, Kapustian V, Anteby E, Linov L. A Radiological Study on the Anatomical Proximity of the Ureters and the Cervix. Int Urogynecol J Pelvic Floor Dysfunct. 2007 Sep; 18(9): 991-5.

12. Kim JH, Moore C, Jones JS, Rackley R, Daneshgari F, Goldman H, Vasavada S. Management of Ureteral Injuries associated with Vaginal Surgery for Pelvic Organ Prolapse. Int Urogynecol J Pelvic Floor Dysfunct. 2006 Sep;17(5): 531-5.

13. Matani YS, Bani-Hani KE, Bani-Hani IH. Ureteric injuries during obstetric and gynecologic procedures. Saudi Med J. 2003 Apr;24 (4): 365-8.

14. Mensah JE, Klufio GO, Ahiaku F, Osafo C, GepiAttee S. Delayed Recognition of Bilateral Ureteral Injury after Gyneacological Surgery. Ghana Med J. 2008 Dec;42(4):133-6.

15. Charles F, dana K et al. Schwartz's Principles of surgery. Ed 9,p 1466

16. Emil Aetal,injuries to the genitor urinary tract. Smith's general urology. Ed 16,p302

17. Rafique M, Arif MH. Management of iatrogenic ureteric injuries associated with gynaecological surgery. Int Urol Nephrol. 2002;34(1):31-5.

\section{How to cite this article?}

R Dushyant, JainS. Hysterectomy: A leading cause of iatrogenic ureteric injuries in obstetric and gynaecologic surgeries. Int J Med Res Rev 2014;2(3):198-201. doi:10.17511/ijmrr.2014.103.08 